\title{
Violência Sexual Contra Crianças e Adolescentes: Um estudo do incesto na perspectiva de gênero
}

\author{
Sexual Violence Against Children and Teenagers: A study on incest under the \\ perspective of gender
}

\author{
Adriana Terezinha Mello Cançado \\ Centro de Ensino Superior dos Campos Gerais \\ adrianatmc@uol.com.br
}

\begin{abstract}
Resumo
Este estudo teve como preocupação averiguar o perfil da violência sexual contra crianças e adolescentes em Ponta Grossa, Paraná, nos anos de 2009 e 2010. Pretendeu, também, discutir a violência sexual contra crianças e adolescentes, de maneira particularizada, enfocando práticas incestuosas numa abordagem de gênero e poder no sentido de revisar agressão sexual intrafamiliar. Para tanto, foram pesquisados Boletins de Ocorrência alocados na Delegacia da Mulher de Ponta Grossa, local de recebimento das queixas de violências contra crianças e adolescente do gênero feminino. Dentre os casos, foram foco do estudo aqueles que dizem especificamente à violência sexual. A violência sexual praticada no âmbito da família ficada constatada na quantificação dos dados, sendo expressiva a prática incestuosa de pais e padrastos em relação às filhas. Nesse sentido, a violência sexual incestuosa foi abordada como uma prática que reafirma elementos simbólicos da masculinidade a partir da dominação sexual das mulheres da família, que têm suas identidades diluídas.
\end{abstract}

Palavras-chave: Violência; violência sexual; incesto; dominação de gênero.

\begin{abstract}
This study was concerned to ascertain the profile of sexual violence against children and adolescents in Ponta Grossa, Paraná, in the years 2009 and 2010. It also wanted to discuss sexual violence against children and adolescents, particularly, with the focusing on incestuous practices according to gender and power approaches, in order to examine sexual assault within the family. To this end, we researched police reports filed in the police station of the Department of Crimes Against Women of the city of Ponta Grossa, as the place that gathers complaints about violence against children and adolescent females. Among the cases found, the focus of this study were those related specifically to sexual violence. The sexual violence within the family environment was found in data quantification, as well as the significant presence of incestuous fathers and stepfathers who practice this act against their daughters. In this sense, the incestuous sexual violence was approached as a practice that reaffirms the symbolic elements of masculinity by means of sexual domination of the women in the family, who have their identities diluted.
\end{abstract}

Keywords: Violence; sexual violence; incest; gender domination. 


\section{Perfil da Violência Sexual Contra Crianças e Adolescentes em Ponta Grossa}

Discorrer sobre o perfil da violência sexual cometida contra crianças e adolescentes em Ponta Grossa, Paraná, nos anos de 2009 e 2010, apresenta-se como um dos objetivos da explanação. Tema recorrentemente anunciado na mídia escrita e televisiva, a violência sexual contra a criança e adolescente apresenta dados alarmantes no Brasil. Desse modo, o estudo do tema em questão contribui para a visibilidade do fenômeno no âmbito local e para agregar aspectos empíricos e teóricos à área do Direito, em perspectiva interdisciplinar com a Sociologia do Direito. Complementarmente, discutir a violência sexual contra crianças e adolescentes, de maneira particularizada, enfocando práticas incestuosas numa abordagem de gênero e poder apresenta-se como objetivo analítico fundamental, no sentido de estabelecer olhares outros para a agressão sexual intrafamiliar.

Os dados sobre a violência sexual foram coletados na Delegacia da Mulher de Ponta Grossa e dizem respeito exclusivamente ao gênero feminino, pois as queixas de violências contras meninas são registradas nesta delegacia. Os registros sobre as violências contra os meninos encontram-se dispersos nas demais delegacias da cidade, conforme os distritos nos quais ocorrem as violências.

Dentre os Boletins de Ocorrências (BO's) que registram violências contras crianças e adolescentes, selecionamos aqueles que tratam especificamente da violência sexual, totalizando o número de 107 casos. Destes BO's variáveis como relação agressor-vítima, idade de agressor e vítima e denunciante foram quantificados, com a finalidade de possibilitar um olhar mais amplo sobre o fenômeno. Assim, a pesquisa desenvolve-se com base em análise documental e em revisão bibliográfica, enquadrando-se também na pesquisa quali-quantitativa.

No sentido teórico, que funcionou como orientador das reflexões sobre o tema recorremos a autores como Alba Zaluar e Maria Stela Grossi Porto, como embasamento da conceituação de violência. Tomaszewski, Schelb e Guerra orientaram as abordagens relativas à violência sexual contra a criança e adolescente. Já a questão simbólica e de dominação da prática do incesto guiou-se pelas ponderações de Lévi-Strauss e Pierre Bourdieu. Mesmo não amparando o percurso teórico-metodológico de maneira explícita e regular, as concepções de poder de Michel Foucault, desenharam algumas ponderações. A categoria de análise de gênero foi adotada para elucidar as relações entre homens e mulheres a partir dos ideais criados para o exercício das funções masculinas e femininas. Este aparato teórico-metodológico orientou a investigação no sentido de fundamentar as diferenças de gênero no âmbito cultural, como criações humanas afloradas em contextos históricos específicos.

As análises e conclusões dos autores citados inspiraram o trato com as fontes e a tentativa de reconstruir a violência sexual incestuosa como uma prática simbólica que, por meio da força, institui e reafirma elementos masculinos de dominação e poder, descaracterizando identidades femininas no âmbito da família. Compreendida como a prática de relações sexuais violentas, física e psicologicamente, entre parentes consanguíneos ou afins, com foco em pais e padrastos, com pessoas menores de dezoito anos, a violência sexual incestuosa extrapola o campo normatizador do direito e revela-se como prática cultural, interdita e transgredida, como forma de reafirmação de posições generificadas na família.

Desse modo, e visando contemplar o objetivo da pesquisa, este trabalho foi organizado em quatro momentos específicos. No primeiro, realizamos breve conceituação da violência nas perspectivas da Antropologia e da Sociologia. Afunilando o tema, na segunda parte, definimos e classificamos a violência contra a criança e o adolescente, com ênfase na violência sexual. No terceiro momento, apresentamos o perfil da violência sexual contra a criança e o adolescente em Ponta Grossa, Paraná, expondo os dados quantificados. Por fim, na parte final, empreendemos a discussão sobre as possibilidades simbólicas e de gênero da violência sexual incestuosa.

\section{Apontamentos sobre a Violência}

Na contemporaneidade, a violência é tratada como uma das grandes preocupações mundiais e compreendida como um fenômeno que afeta a sociedade como um todo e o indivíduo isoladamente. A prática da violência não atinge a população de maneira homogênea, pois suas variações qualitativas e quantitativas acontecem relacionadas às variações de idade, gênero, etnia, moradia ou condições sociais, econômicas, políticas. Além da concepção de relação entre múltiplas variáveis sociais, a violência revela-se uma forma de domínio e opressão desencadeada por indivíduos a outros indivíduos.

A antropóloga Alba Zaluar (1999) enfatiza a polifonia do termo violência e explica sua origem na expressão latina violentia, que remete a vis, cujo significado é força, vigor, emprego de força física. Ao ultrapassar limites de regras que ordenam relações sociais, esta força torna-se violência. Nesse sentido, é 
a percepção do limite transposto e o sofrimento provocado que caracteriza um ato como violento. Não é possível, portanto, de antemão, definir substantivamente a violência. Nesse sentido, a violência é definição relativizada, vinculada a contextos específicos. Tal consideração põe em questionamento a existência de valores universais, atemporais e transcendentais.

Em semelhante viés teórico, a socióloga Maria Stela Grossi Porto (2006) explicita que um dos elementos mais complexos na definição da violência é justamente não haver uma definição abstrata, que possa ser aplicada a qualquer sociedade. No entanto, tomando cuidado para evitar o relativismo, Porto (2006) defende que toda vez que a integridade física e moral da pessoa é atingida ocorre um ato violento. Mesmo diante de uma suposta orientação conceitual, para a autora permanece ainda a ambiguidade, pois será necessária a compreensão de integridade e dos critérios para sua classificação. Ressaltando a concretude do fenômeno, Porto orienta que, objetivamente, violência seria aquilo que as estatísticas assinalam como tal. No âmbito da subjetividade, porém, violência é aquilo que as pessoas representam como violência. Conclui a socióloga que pensar a violência a partir destes parâmetros significa abrir mão de julgamentos normativos ou valorativos, pois o que está em questão não é o legal ou normativamente correto, mas o efetivamente vigente.

Ao discutir a violência, o sociólogo Marcondes Filho (2001) vincula violência às concepções de abuso, excesso e desejo. Para o autor, excesso não é senão outro nome para o desejo. Decorre desta premissa que é preciso considerar a existência de um componente de prazer e satisfação nos atos violentos e, em decorrência, em sua definição. Também considerando o desejo, por sua vez, o antropólogo Gilberto Velho (1996) descreve a violência como possibilidade de uso da força física na imposição de vontade ou desejo. Esta imposição constitui-se por práticas de poder.

Diante do exposto, compreende-se violência como ato opressivo, instituído por relações entre pessoas desiguais em poder e desencadeado por imposição de desejos e vontades. No entanto, corrobora-se os pressupostos elucidados por Zaluar e Porto, enfatizando-se a necessidade de contextualização do ato violento e das percepções sociais dele advindas.

Complementarmente às concepções apresentadas, no âmbito jurídico, o fenômeno da violência é vista como uma violação do direito de liberdade, da vontade por meio da coação. Maria Regina Fai de Azambuja (2004) destaca que a violência, em seu sentido amplo, contraria o princípio da dignidade humana. Na esfera do direito a violência é classificada, através de suas intencionalidades, em violência física, psicológica e sexual. A primeira, caracteriza-se causa danos à integridade física da pessoa por meio da força física, com ou sem uso de armas. A segunda, não deixa marcas visíveis, abalando a esfera do emocional, através da intimidação, manipulação, ameaça e discriminação. Por fim, a violência sexual identifica-se pela ação do agressor em obrigar a vítima a manter contato sexual por meio da força, da coerção, da chantagem, anulando ou limitando a vontade desta.

Até aqui discorremos sobre a violência sob uma perspectiva generalizante, sem foco específico em qualquer grupo social. No entanto, tendo como objeto central a violência praticada contra crianças e adolescentes torna-se relevante o esboço de considerações sobre estas agressões em particular.

\section{Violência Contra Crianças e Adolescentes}

Crianças, conforme prevê o Estatuto da Criança e Adolescente (ECA), são pessoas com até 12 anos incompletos e adolescentes, pessoas entre 12 e 18 anos incompletos (ECA, 2008). Criança, para Dermival Ribeiro Rios (2004, p. 199) é o "ser humano no começo da existência, pessoa ingênua ou infantil". O historiador Phillipe Ariés orienta que a criança é também uma construção histórica, tendo sido vista por inúmeros ângulos conforme as conjunturas de cada período histórico. $\mathrm{Na}$ contemporaneidade, constatamos a ocorrência de preocupações advindas de vários campos de conhecimento sobre as violências praticadas contra pessoas menores de 18 anos. A violência permeia o cotidiano de jovens de um modo ou de outro, como vítimas e como agressores. Nesse sentido, conclama-se abordagens multidisciplinares para observar, analisar e propor estratégias para a prática recorrente das violências que assolam crianças e adolescentes.

As violências cometidas contra crianças e adolescentes revelam um grau de singularidade: o baixo nível de compreensão das vítimas sobre as motivações das práticas, concretizadas muitas vezes, por aqueles que jurídica e moralmente deveriam zelar pelos cuidados e responsabilidades em relação às vítimas.

As práticas violentas voltadas para as crianças e adolescentes também são classificadas em física, psicológica, sexual e a negligência, sendo esta última caracterizada pela falta de provisão das necessidades físicas e emocionais da criança ou adolescente, assim como pelo abandono parcial ou temporário

A violência física, cuja característica é o poder disciplinador do adulto e a desigualdade entre criança e adulto se refere a uma ação única ou repetida, intencionalmente, que cause dor física, provocando

Adriana Terezinha Mello Cançado 
consequências leves ou extremas. Por sua vez, a violência psicológica ampara-se em conjunto de atitudes, palavras ou ações que bloqueie a autoestima da criança e do adolescente causando um enorme sofrimento mental, comprometendo sua sociabilidade (TOMASZEWSKI , 2004).

Dentre as violências apresentadas destaca-se, neste trabalho, em sua forma mais silenciosa: a violência sexual contra a criança e o adolescente na esfera do privado, entre as relações afetivas e de parentesco. Configurada como todo ato ou jogo sexual, hetero ou homossexual, no qual um adulto objetiva, em relação à criança e adolescente, estímulo ou satisfação sexual destas ou daquele (LIBORIO, 2003). Este tipo de violência é um acontecimento de proporções mundiais que ocorre sem distinção de classes sociais, compreendendo relações de gênero, posição da criança e adolescente, papel das famílias no interior de suas próprias estruturas. Constitui-se não só numa violação de direitos como violação sexual e de diretos particulares de pessoa em desenvolvimento, pois as vítimas, na maioria dos casos, apresentam consequências físicas e emocionais, como altos níveis de ansiedade, baixo-estima, distúrbios no sono e na alimentação, problemas no aprendizado e na concentração, ente outras características relatadas pela Associação Brasileira Multiprofissional de Proteção à Infância e a Adolescência (ABRAPIA).

Retomando as ponderações de Zaluar (1999) e Porto (2006), podemos afirmar que a violência contra crianças e adolescentes encontra-se conceitualmente definida pela percepção de sofrimento que causa e pelo rompimento do adulto de regras que regem as relações aceitas social e juridicamente nas sociedades ocidentais no trato com as crianças e adolescentes. Tendo como resultado concreto danos a integridade física e moral, as agressões sexuais constituem-se em atos tipificados como violências, amplamente registrados em estatísticas.

A violência sexual contra a criança é tipificada como crime, em alguns casos, na legislação brasileira. Alguns desses crimes encontram-se previstos no Código Penal, recentemente alterado pela Lei 12.015, de 7 de agosto de 2009. O art. 213, Título: 'Dos Crimes contra a Dignidade Sexual', Capítulo: 'Dos Crimes contra a Liberdade Sexual', regulamenta o crime de estupro, hoje fundido com o atentado ao pudor, agravado no parágrafo $1^{\mathrm{o}}$ quando a vítima for menor de 18 anos ou maior de 14 anos. Em relação aos menores de 14 anos, reserva-se o Capítulo II: 'Dos crimes sexuais contra vulnerável'. Neste capítulo são tipificados os crimes de estupro de vulnerável (art. 217A), corrupção de menores (art. 218), satisfação de lascívia mediante presença de criança ou adolescente (art. 218-A), prostituição ou outra forma de exploração sexual (art. 218-B) ${ }^{1}$. Ensina Mirabete (2007) que o crime de estupro exige constrangimento de qualquer natureza que obrigue a conjunção carnal. Por sua vez, os atos de facilitar, induzir à prática ou a presenciar atos sexuais são tipificados na corrupção de menores (SILVA, 2005).

Assim, nos limites deste estudo interessa-nos refletir sobre a violência sexual contra crianças e adolescentes, compreendida como o conjunto de atos nos quais crianças e adolescentes se encontram coibidos, pela força física e/ou por manipulações emocionais ou psicológicas a contatos sexuais com adultos. Esta violência é ainda mais singular quando acontece no espaço privado da criança e adolescente.

Orienta o Ministério da $\operatorname{Saúde}^{2}$ que a violência intrafamiliar é toda ação ou omissão que prejudique o bem-estar, a integridade física, psicológica ou a liberdade e o direito ao pleno desenvolvimento de outro membro da família. A violência é cometida por alguém da família, incluindo aqueles que assumem o exercício de funções parentais, mesmo sem laços consanguíneos Esta concepção não é estabelecida pelo espaço físico no qual ocorre a violência, mas pelas relações nas quais a violência se constrói e se efetua. Já a violência doméstica inclui outros membros da família, sem função parental, que convivam no espaço doméstico. Incluem-se aí empregados/as, pessoas que convivem esporadicamente, agregados.

A violência sexual, também conhecida como abuso sexual, cometida no âmbito privado ocorre quando um parente ou conhecido tem por costume acariciar o corpo da criança, com a afirmação de dar carinho e afeto, todavia com a intenção de se estimular sexualmente (SCHELB, 2004). Consiste numa transgressão do poder disciplinador e coercitivo do adulto, que impõe rígida hierarquia, instituindo uma espécie de pacto de silêncio. Neste processo de dominação, a criança e o adolescente vivenciam graduais etapas de vitimização, que podem se prolongar por vários meses ou mesmo anos, ferindo direitos essenciais da criança e do adolescente, como pessoa e negando valores humanos fundamentais como a vida, a liberdade e a segurança (GUERRA, 2008).

Objetivando estudar o abuso sexual praticado contra crianças e adolescentes, com foco nas ocorrências da esfera privada, realizou-se levantamento de dados nos Boletins de Ocorrência da Delegacia da Mulher, no decorrer dos anos de 2009 e 2010, e que arquiva exclusivamente casos de vítimas do gênero feminino. Da totalidade dos casos registrados, selecionamos 107 relativos à violência sexual. 


\section{Perfil da Violência Sexual Contra Crianças e Adolescentes em Ponta Grossa}

Partindo de uma análise mais ampla, na qual se tenta traçar um perfil da violência sexual contra a criança e adolescente na cidade de Ponta Grossa, estabelecemos algumas variáveis como denunciantes, idade agressor e vítima, local de ocorrência da violência e, como ponto central, a relação entre agressor e vítima.

No que diz respeito aos denunciantes, isto é, pessoas que fazem o registro da violência, as mães aparecem em expressivo número com 69 denúncias $(64,4 \%)$, seguido pelo pai com dez registros $(9,3 \%)$. Outros familiares também denunciam em baixa proporção, como avós $(5,6 \%)$, tias $(3,7 \%)$ além da própria vítima $(3,7 \%)$. Estes dados demonstram ausência da figura masculina na família ou a permanência da prática cultural e de gênero que institui os cuidados com a sexualidade das filhas à mãe.

Referente a idade da vítima, a análise documental indica que há uma concentração de casos abaixo dos catorze anos, praticados contra crianças e adolescentes caracterizados como vulneráveis no CPB, com 86 casos $(80,37 \%)$. Destes, $68(79,70)$ concentram-se entre os sete e catorze anos.

Entre os quinze e dezoito anos, o número de registros encontra-se em 18 casos $(16,82 \%)$. Três são os casos cuja idade não foi informada. A idade de 14 anos concentra o maior número de ocorrências, com 15 casos.

Quanto a idade do agressor, dos treze aos vinte anos há o registro de doze casos $(11,21 \%)$; entre vinte e um e trinta anos, vinte e quatro registros $(22,42 \%)$; entre trinta e um e quarenta anos, quinze casos $(10,01 \%)$; entre quarenta e um e cinquenta anos, dez casos (9,34\%); entre cinquenta e um e sessenta anos, registram-se dez casos (9,34\%); por fim entre sessenta e um e sessenta e nove anos, o número de três casos $(2,80 \%)$. No entanto, o número de casos nos quais a idade não foi informada é expressivo, com 33 registros $(30,84 \%)$. Observa-se que a faixa etária do agressor, nos registros estudados, localiza-se entre os vinte e trinta anos.

Sobre a relação agressor-vítima, dos 111 agressores - em quatro casos há dois agressores -, a violência intrafamiliar, caracterizada por ser cometida por alguém da família, inclusive aqueles que assumem funções parentais, sem vínculos consanguíneos, apresenta-se com o número de cinquenta e dois casos. Nesta classificação consideramos tio, avô, padrasto, pai, padrinho, cunhado, primo, madrasta, irmão, enteado do pai e mãe. Se olharmos para a violência doméstica, no sentido de acrescentar pessoas sem função parental, mas que convivem no espaço doméstico com a criança e adolescente teremos trinta e quatro denúncias. Nessa análise incluem-se os vizinhos com dez queixas, pai de amiga da vítima com um registro, conhecidos da vítima com seis registros, namorados com treze registros professores com dois registros, patrão da mãe e pedreiro com um registro, respectivamente.

Diante dos dados expostos é possível inferir que a maior parte dos casos de violência sexual cometida contra meninas menores de dezoito anos, em Ponta Grossa, ocorre na esfera privada, com 86 casos (77,47\%), sendo que $80,37 \%$ atingem menores de catorze anos. Esta violência é praticada por homens conhecidos da criança $(30,63 \%)$, que deveriam ter responsabilidades parentais ou laços sanguíneos $(46,84 \%)$ sobre ela. Na esfera da violência doméstica, as queixas contra os namorados resultam em maior número com 11,71\%; vizinhos aparecem como agressores em potencial, com $9,9 \%$ das queixas, seguidos de 'conhecidos da família', com $5,40 \%$ das queixas. Os demais registros ficam fragmentados nas outras classificações expostas acima.

Considerada como um espaço de circulação e exercício da sociabilidade, a escola ou o caminho para a escola aparecem também como lugares para a prática das violências sexuais. Dois professores foram denunciados e três 'desconhecidos' indicados como agressores que interceptaram as vítimas no caminho para a escola, sendo que uma denúncia indica o transporte escolar como local da abordagem.

O número de casos cometidos por pessoas da esfera das relações familiares e sociais das crianças e adolescentes torna-se ainda mais visível quando comparada ao agressor 'desconhecido', com vinte e duas queixas $(19,81 \%)$ e dois casos nos quais a relação não foi informada $(1,80 \%)$.

Podemos, assim, concluir que a violência sexual contra meninas, menores de dezoito anos, em Ponta Grossa, por meio do estudo dos Boletins de Ocorrência da Delegacia da Mulher, caracteriza-se por ocorrer no âmbito privado - intrafamiliar e doméstico -, praticada por homens entre vinte e trinta anos em relação a meninas com idade predominante abaixo dos catorze anos e, dentre estas idades há concentração entre os sete e catorze anos.

\section{Violência Sexual Incestuosa como Prática Generificada e Simbólica}

O incesto, identificado como a prática de relações sexuais entre pessoas portadoras de laços 
consanguíneos, afins ou adotivos (RANGEL, 2009) ou como relações sexuais praticadas entre membros de uma mesma família (DUROZOI; RUSSEL, 1993), pode ser refletido a partir da visibilidade atribuída aos dados da violência sexual praticada contra meninas menores de catorze anos, em Ponta Grossa.

Considerado tabu em várias sociedades, em diferentes espaços e tempos, excetuando algumas poucas como, por exemplo, o casamento de irmãos nas famílias reais do Egito Antigo ou do Império Inca, o incesto tornou-se, inicialmente, objeto da Antropologia e da Sociologia, sendo estudado pelo antropólogo Claude Lévi-Strauss (2008).

Negando-se a enfocar exclusivamente a proibição do incesto em termos biológicos ou psíquicos, LéviStrauss chama atenção para os aspectos sociais da prática em oposição à sua natureza. Por meio da abordagem estruturalista, o antropólogo procura explicações relacionais para a proibição, levando em conta a posição ocupada pelas pessoas nas relações incestuosas em um determinado sistema de parentesco. Dito de outro modo, Lévi-Strauss procura entender porque pessoas que estão na posição de pai e irmão não podem reivindicar como esposa as mulheres que estão na posição de filhas e mães. Responde o antropólogo que esta é uma norma social por meio da qual as mulheres são mantidas como objeto de troca na esfera do grupo e não do privado, como um incentivo a exogamia. Trata-se aqui de uma economia no mercado matrimonial, de troca de mulheres como base de qualquer instituição matrimonial, que envolve homens e mulheres. Rangel (2009) pondera que a proibição do incesto institui não só o casamento, mas também, e simultaneamente, o parentesco. Com efeito, uma estrutura de parentesco por mais simples que seja, não pode se restringir jamais ao núcleo familiar composto pura e simplesmente de um casal e seus filhos, pois inclui a relação entre aquele que cede a mulher (o irmão ou pai da noiva) e aquele que a recebe (o marido), pois é essa 'troca' que fornece o eixo em torno do qual as relações de filiação e de afinidade se constituem.

Explicações sobre a proibição do incesto também amparam-sese amparam sobre aspectos biológicos, instintivos, como o fato de ser uma defesa da espécie humana contra consequências genéticas resultantes da procriação entre parentes próximos. Esta explicação é frágil, pois as relações incestuosas recaem sobre relações de parentescos e não de consanguinidade, sendo que a interdição pode atingir alguns graus de parentesco. Outra explicação fundamenta-se no horror instintivo à prática desta relação que negaria a excitabilidade da ação. Rangel (2009), uma vez mais explicita que frequentes violações da proibição indicam que não há nenhum horror instintivo a esse tipo de relação e que é preciso observar que se é considerado interdito, o incesto ameaça de alguma forma a ordem social.

Desejos incestuosos, suas proibições e desdobramentos foram estudados por Freud, sob a denominação de Complexo de Édipo. Neste complexo, a criança sente amor e ciúmes em relação a um dos pais. A criança se apaixona por um dos pais e vê o outro como empecilho para a realização de suas fantasias. É, para Freud, um sentimento inconsciente, integrante do desenvolvimento psicológico da criança. Trata-se da imposição de limites ao desejo, a interdição aos impulsos incestuosos. Maria Berenice Dias (2010) afirma que a interdição do incesto define as gerações, a função de cada pessoa no núcleo familiar e deixa claro que os parceiros dos filhos devem provir de famílias diferentes, concordando com os ensinamentos de Lévi-Strauss. Para Lacan, a interdição do incesto, por ele chamada de Lei do Pai, impede o menino de relacionar-se sexualmente com sua mãe. O pai tem função simbólica representando a proibição à desobediência. Assim, "o incesto configura o gozo a que o filho aspira, imaginado, desejado, sonhado, a que o sujeito não tem acesso em razão da intervenção do pai" (DIAS, 2010, p.157).

Forward e Buck (1989) orientam duas definições para o incesto. A primeira é a legal, caracterizada pela relação sexual entre indivíduos de um grau muito próximo de parentesco, incluindo uma variedade enorme de experiências, como carícias, sexo oral e fotografias. A segunda, tratada como definição psicológica é muito mais abrangente, por conceituar como incesto qualquer forma de contato abertamente sexual entre pessoas que tenham um grau de parentesco ou mesmo que acreditem tê-lo, incluindo padrasto e madrasta, meio irmãos, avós por afinidades. Finalizam os autores afirmando que se a criança depositar confiança no parente ou se a figura de pai e mãe for violada por qualquer ato de violência sexual trata-se de incesto (FORWARD; BUCK, 1989, p.11).

No Brasil, o casamento entre parentes é regulado pelo Código Civil de 2002, no artigo 1521:

Art. 1.521. Não podem casar:

I - os ascendentes com os descendentes seja o parentesco natural ou civil;

II - os afins em linha reta;

III - o adotante com quem foi cônjuge do adotado e o adotado com quem o foi do adotante;

IV - os irmãos, unilaterais ou bilaterais, e demais colaterais, até o terceiro grau inclusive; 


\author{
V - o adotado com o filho do adotante; \\ VI - as pessoas casadas; \\ VII - o cônjuge sobrevivente com o \\ condenado por homicídio ou tentativa de \\ homicídio contra o seu consorte.
}

Este artigo proíbe a união entre ascendentes e descendentes na linha reta até o infinito, sob a argumentação da eugenia e da moralidade. O impedimento estende-se aos irmãos nascidos do casamento ou não, assim como parentes que descendem de um tronco comum sem descenderem uns dos outros, exceção feita a tios e sobrinhos, desde que atestada a saúde de ambos confirmando não haver risco para os filhos gerados. As situações abrangidas pelos incisos referem-se aos impedimentos por parentesco. Já os impedimentos por afinidade baseiam em fundamentos morais, atingindo o parentesco que se estabelece em virtude de casamento ou união estável entre duas pessoas e os parentes de um e outro, limitando-se ao primeiro grau. $\mathrm{O}$ impedimento de adoção, baseado na moral e na preservação da legitimidade das relações familiares, proíbe casamento entre adotante e adotado, com seus companheiros ou seus filhos.

A normatização positivada que rege as relações de união conjugal entre parentes, baseada em argumentos morais e eugênicos, não impedem a ocorrência de violências sexuais praticadas por membros masculinos da família, consanguíneos ou por afinidade, contra crianças e adolescentes, majoritariamente do gênero feminino. É o que se constata nos dados analisados sobre a violência sexual contra crianças e adolescentes em Ponta Grossa. Dos 107 casos denunciados, 46,84\% são cometidos por homens possuidores de laços sanguíneos ou de afetividade em relação às meninas. Deste número, 23,42\% são cometidos pelos pais biológicos ou pelos padrastos. Não há aqui a formalização de laços conjugais, extrapolando a normatização positivada. Em termos jurídicos, o agressor terá praticado estupro com aumento da pena por ter relação de parentesco com a vítima, conforme preconiza o artigo 226 do Código Penal Brasileiro (CPB):

Art. 226 - A pena é aumentada:

[...]

II - de metade, se o agente é ascendente, padrasto ou madrasta, tio, irmão, cônjuge, companheiro, tutor, curador, preceptor ou empregador da vítima ou por qualquer outro título tem autoridade sobre ela (grifo nosso).
O que podemos observar é que o incesto, compreendido como vivência sexual comum entre parentes consanguíneos e por afinidade, não configurase como proibição legal, mas como interdito cultural, conforme orienta Lévi-Strauss.

Judith Butler (2003, p.72), ao analisar o incesto afirma que o "fato da proibição existir não significa absolutamente que funcione". Prossegue, defendendo que a existência do incesto e dos desejos e práticas decorrentes são produzidos justamente em virtude da erotização desse tabu. A questão central, colocada por Butler, reside na indagação de como as fantasias são produzidas e instituídas em função da proibição do incesto. A partir de Lévi-Strauss, Judith Butler argumenta que o tabu do incesto, como forma de exogamia, traduz que a mulher funciona como um termo relacional entre grupos de homens não possuindo identidade, refletindo a identidade masculina. Trata-se de uma identidade na diferença, visto que os grupos masculinos exógenos possuem identidades semelhantes: masculinos, patriarcais e patrilineares. É uma identidade cultural masculina que a tudo abrange.

Neste ponto, é possível olharmos a prática incestuosa nas violências sexuais cometidas contra meninas, como uma questão generificada e de poder. O cenário destas específicas relações de poder é o espaço privado da família, espaço este no qual, tradicionalmente, impera o poder masculino. A variável central é a prática da satisfação sexual deste personagem masculino que, por meio de atos de poder desiguais, submete uma figura feminina, a menina da família, ao papel de objeto de prazer. Ocorre um deslocamento das posições e disposições familiares, para citar Bourdieu, pois a identidade da criança diluise nas representações identitárias do poder masculino e substitui a figura da mulher-esposa-companheira.

Tradicionalmente, a violência de gênero tem sido exercida pelos homens sobre as mulheres e, "estatisticamente falando, sobre suas próprias mulheres, sejam elas companheiras ou filhas", conforme orienta Muszkat (2001, p.227). Elementos discursivos da chamada cultura patriarcal, inegavelmente, ainda encontram-se presentes nas subjetividades contemporâneas, instituindo homens como detentores de prestígio e poder e mulheres portadoras de sedução e fraqueza, o que as tornam vítimas em potencial e naturalizadas. Prossegue Muszkat (2001, p.229), orientando que a violência cometida por homens, no âmbito privado, não deve ser vista como uma doença, nem instinto, mas como "uma manifestação do domínio do homem sobre a mulher". Nesse contexto cultural, de tutela e dependência feminina, as mulheres sempre foram tratadas como

Adriana Terezinha Mello Cançado 
objeto de posse do grupo masculino. Assim, dominá-la sexualmente ou bater nela tornam-se práticas naturalizadas e integrantes das representações de masculinidade.

No caso da violência sexual incestuosa, podemos inferir a naturalização do uso do corpo feminino, cuja representação é o papel de filha, como uma prática do poder masculino no sentido da dominação do espaço privado e doméstico. Desse modo, o que se verifica na expressão das forças e representações que interagem, na esfera privada das famílias é de fato a existência de conflitos que se traduzem em relações de poder, estabelecidas historicamente, entre os gêneros. O poder é algo que se expressa de múltiplas formas, não estando restrito ao físico, manifestando-se também de maneira simbólica (FOUCAULT,1998). No caso das violências sexuais incestuosas é possível perceber a existência de dois tipos de poder, o exercício do poder transmutado em violência sexual e o exercício do poder simbólico entre homens e mulheres, nos papéis de pai-marido e mãe-esposa-filha.

Pode-se, assim, constatar, através dos estudos de gênero, que a relação entre o feminino e o masculino funciona de uma maneira assimétrica e desigual, sob a forma de ascendência social que se reproduz com base num processo de naturalização. Pierre Bourdieu (1999) trata dessa condição de dominação dos homens sobre as mulheres, detectando a presença de um modelo de longa duração que referenda o exercício deste poder enquanto construção cultural e histórica que vem permeada pela necessidade do reconhecimento social. Dessa forma, ser homem ou ser mulher representa um lugar na sociedade e um papel a cumprir, embutido na representação que recebe o reforço permanente e público de todo o conjunto social,

Ainda segundo Bourdieu (1995), a dominação masculina é algo que está presente em estado objetivado tanto no mundo social como incorporado no habitus, e se constrói a partir de condições reais no caso da violência sexual em questão. Nesta situação, os homens exercem uma autoridade sobre as mulheres da família e, simbolicamente, reafirmam elementos de masculinidade, como o controle pela força dos membros do núcleo familiar. A prática transgressora do tabu do incesto pode representar acúmulo de capital simbólico masculino, no sentido do reconhecimento do poder sexual masculino na esfera do privado (BOURDIEU, 1989). Retomando as análises de Butler, é possível olhar para a violência sexual incestuosa como uma prática que também dilui as identidades femininas na família, mulher-companheira sexual-filha se confundem e confirmam a identidade masculina como dominador sexual.

Assim, a transposição de um limite social e moral, como a proibição do incesto, como se constituir em violência sexual quando praticada com menores de dezoito anos resultando no abalo à integridade física e psicológica da criança e adolescente, violando direitos e contrariando o princípio da dignidade humana. Nesse sentido, juridicamente ocorre a intervenção do poder estatal concretizando a punição pelo crime de estupro agravado pelas relações de parentesco consanguíneos ou afins. No campo mais amplo das relações sociais e culturais, a transgressão do tabu pode representar simbolicamente o exercício de estruturas masculinas de poder. Através dessa prática transgressora, o homem reafirma sua masculinidade e virilidade, reafirmando a hierarquia familiar e mantendo sob domínio as figuras femininas, cujas identidades de gênero se confundem no jogo simbólico da dominação sexual.

\section{Considerações Finais}

O diagnóstico da violência sexual contra a criança e adolescente, com enfoque no âmbito privado, constitui-se um desafio, por sua complexidade. Esta violência está, sem dúvidas, vinculada ao campo de proteção dos direitos humanos e sexuais, pois compromete o desenvolvimento físico, psicológico e emocional da criança e adolescente, produzindo sequelas, muitas vezes, irreversíveis. Porém, encontrase também no espaço simbólico quando práticas violentas e incestuosas são percebidas como reafirmações de elementos identitários masculinos.

Notamos acerca dos dados compilados nos anos de 2009 e 2010, que há uma concentração numérica expressiva em casos de violência sexual praticada contra a criança e adolescente no âmbito privado, nos quais as idades das vítimas oscilam entre um e dezoito anos de idade, com ênfase no grupo de sete a catorze anos. Os agressores são homens com os quais as vítimas possuem algum tipo de vínculo, sanguíneo ou por afinidade. Destes, pais e padrastos representam número expressivo. Quanto as idades dos agressores, o grupo entre vinte e quarenta anos apresenta trinta e nove casos; entre quarenta e um e sessenta, trinta caso, demonstrando grande variação etária. As denúncias sobre a violência competem à mãe, predominantemente.

A violência sexual, principalmente a incestuosa, contra criança e adolescente deve ser discutida em espaços formais, mas também no próprio ambiente familiar e da escola, para que vítima em potencial possa compreender atos caracterizadores do abuso sexual. Entendemos que o cumprimento dos direitos da criança e adolescente deve ser prioridade da sociedade como um todo, contribuindo para o efetivo

Adriana Terezinha Mello Cançado 
exercício da cidadania e da dignidade humana.

Para a efetivação concretização dos direitos fundamentais das crianças e adolescentes, requer que o direito volte-se para as questões de gênero, compreendo as relações entre masculino e feminino em suas singulares variáveis culturais e contribua para a visibilidade de fenômenos que ainda insistem em constituir-se nas relações familiares, intensificando desigualdades de dominações por meio do uso da força física e simbólica.

1 A exploração sexual contra pessoas maiores de 18 anos encontra-se regulamentado no Capítulo V 'Do lenocínio e do tráfico de pessoa para fim de prostituição ou outra forma de exploração sexual', do Código Penal Brasileiro (CPB).

2 BRASIL. Ministério da Saúde. Violência intrafamiliar. Cadernos de Atenção Básica. Orientações para a prática em serviço. Disponível em $<$ http://bvsms.saude.gov.br/bvs/publicacoes/cd05_19.p df $>$

\section{Referências}

ABRAPIA. Associação Brasileira Multiprofissional de Proteção à Infância e Adolescência (ABRAPIA). Abuso Sexual contra crianças e adolescentes: proteção e prevenção. Guia de orientação para educadores. Rio de Janeiro: Autores \& Agentes, 1997.

ARIÈS, Philippe. História Social da Criança e da Família. 2 ed. Rio de. Janeiro: LTC, 1981.

AZAMBUJA, Maria Regina Fay de. Violência Sexual Intrafamiliar: É possível proteger a criança? Porto Alegre: Livraria do Advogado, 2004.

BOURDIEU, Pierre. A dominação masculina. Educação e Realidade, v. 20, n. 2, p. 133-184, jul./dez. 1995.

O Poder simbólico. Lisboa: Difel, 1989.

BRASIL, Código Civil (2002) Código civil 2002, promulgada em 10 de janeiro de 2002, 5. ed. São Paulo: Saraiva, 2008. p.570 (série Vademecum).

BRASIL. Código Penal (1990). Código Penal: Parte Especial: promulgado em 7 de dezembro de 1940. 5. ed. São Paulo: Saraiva, 2008. p.570 (série Vademecum).

BRASIL. Estatuto da Criança e Adolescente (1990). [Disponível em www. planalto.gov.br/ccivil_03/Leis/L8069.htm]

BRASIL. Ministério da Saúde. Violência intrafamiliar. Cadernos de Atenção Básica. Orientações para a prática em serviço. [Disponível em http://bvsms.saude.gov.br/bvs/publicacoes/cd05_19.pd f]

BUTLER, Judith. Proibição, psicanálise e a produção da matriz heterossexual. In: BUTLER, Judith. Problemas de gênero. Feminismo e subversão da identidade. Rio de Janeiro: Civilização Brasileira, 2003, p.61-118.

DIAS, Maria Berenice. Incesto e o mito da família feliz. In: DIAS, Maria Berenice. (coord.) Incesto e alienação parental. Realidades que a Justiça insiste em não ver. São Paulo: Revista dos Tribunais, 2010, p. 153-185.

DUROZOI, Gerard; ROUSSEL, André. Dicionário de Filosofia. São Paulo: Papirus, 1993.

FORWARD, Susan; BUCK, Craig. A traição da inocência. $O$ incesto e sua devastação. Rio de Janeiro: Rocco, 1989.

FOUCAUlt, Michel. Microfísica do Poder. Rio de Janeiro: Graal, 1998.

GUERRA, Viviane Nogueira de Azevedo. Violência de pais contra filhos - a tragédia revisitada. 6 ed. São Paulo: Cortez, 2008.

LÉVI-STRAUSS, Claude. As estruturas elementares do parentesco. 4.ed. Rio de Janeiro: Vozes, 2008.

MARCONDES FILHO, Ciro. Violência fundadora e violência reativa na cultura brasileira. São Paulo em Perspectiva, vol.15, n.2, p. 20 - 27, 2001.

MIRABETE, Julio Fabbrini. Manual de Direito Parte Especial. 25ª ed. São Paulo: Atlas. 2007.

MUSZKAT, Malvina Ester. Violência de gênero e paternidade. In: ARILHA, Margareth; UNBEHAUM, Sandra; MEDRADO, Benedito (Org.) . Homens e masculinidades: outras palavras. São Paulo: ECOS, 1998, p. 215 - 234. 
Violência Sexual Contra Crianças e Adolescentes:

Um estudo do incesto na perspectiva de gênero

PORTO, Maria Stela Grossi. Crenças, valores e representações sociais da violência. Sociologias, Porto Alegre, n. 16, p.250-273, jul./dez. 2006.

RANGEL, Patrícia Calmon. Abuso sexual intrafamiliar recorrente. $2^{\text {a }}$ ed. Curitiba: Juruá, 2009.

RIOS, Dermival Ribeiro. Minidicionário Língua Portuguesa. São Paulo: Difusão Cultura do Livro. 2004.

SCHELB, Guilherme. Violência e criminalidade infanto juvenil. Brasília: Thesaurus Editora, 2004.

SILVA, Tadeu Aantônio Dix. Crimes Sexuais. Reflexões sobre a nova Lei 11.106/2005. São Paulo: Mizuno. 2005.

TOMASZEWSKI, Adauto de Almeida. Separação, Violência e Danos Moraes - A tutela da personalidade dos filhos. São Paulo: Paulistanajur, 2004.

VANIER, Alain. Direito e Violência. Ágora: Estudos em Teoria Psicanalítica, v. 7, n.1, jan./jul. 2004.

VELHO, Gilberto. Violência, reciprocidade e desigualdade: uma perspectiva antropológica. In: VELHO, Gilberto; ALVITO, Marcos. (orgs.). Cidadania e Violência. Rio de Janeiro: UFRJ, 1996. p. $10-24$.

ZALUAR, Alba. Um debate disperso: violência e crime no Brasil da redemocratização. Perspectiva, v. 13, n. 3, p. $3-17$, jul./set., 1999. 